\title{
Partially selective search of memory for letters and digits
}

\author{
CHARLES CLIFTON, JR. and ERIC BREWER \\ University of Massachusetts, Amherst, Massachusetts 01002
}

\begin{abstract}
Three experiments failed to provide evidence that subjects could search just the digits, or just the letters, of a mixed list of digits and letters in deciding whether a probe item was a member of the list. Providing a precue as to the category of the probe shortly before the presentation of the probe decreased the time needed to encode it, but did not change the memory search process. Repeating the category of the probe from one trial to the next, however, did change the pattern of memory search. A "partially selective search" model was proposed which claimed that a mixed list was stored as two categorized sublists, and that a self-terminating search of the sublists could occur in which the first sublist searched was the one which had been probed on the previous trial.
\end{abstract}

If a person is asked to decide whether a probe is a member of a previously memorized short list of simple target items, his reaction time (RT) increases linearly with the length of the list, at a rate of approximately $35 \mathrm{msec} /$ item (Sternberg, 1966, 1969a). The original, and most elegant, account of this finding is that the person serially and exhaustively searches his memory of the target items, comparing each one against the probe item.'

Such an exhaustive search process seems an inefficient way of retrieving information from large, structured memory ensembles, and existing data (e.g., Herrmann, McLaughlin, \& Nelson, 1975) indicate that subjects use information about the categorical structure of long lists to shortcut memory search (cf. Homa, 1973). Several researchers have asked whether categorical structure can be used to guide memory search of subspan or near-span lists, about which decisions would otherwise be made on the basis of an apparently exhaustive search. Two lines of evidence indicate that such guided, or selective, search may occur. First, when a list composed of items in one category (e.g., letters) is probed with an item from a different category (e.g., digits), the function relating $\mathrm{RT}$ to the number of memorized items is flatter than when the probe is from the same category as the list (Barron, 1975; Lively \& Sanford, 1972). Second, when a memorized list contains items from several different categories, there seem to be some conditions under which RT is an additive function of the number of items in the probed category and the number of categories represented in the list, rather

This research was supported in part by National Institute of Mental Health Research Grant MH-23939. The authors would like to thank Jerome Myers, Alexander Pollatsek, and Patricia Sorce for their helpful comments on earlier versions of this manuscript, and acknowledge the generous support for the preparation of this manuscript provided by the Department of Psychology of Stanford University. Requests for reprints should be addressed to Charles Clifton, Department of Psychology, University of Massachusetts, Amherst, Massachusetts 01002. than a linear function of the total number of items in the list (Clifton \& Gutschera, 1971; Homa, 1973; Naus, 1974; Williams, 1971). Such a finding indicates that subjects first compare the category of the probe with the categories represented in the list, and then, if a category is found to match, compare the probe item with the items in the appropriate category.

However, the available data do not conclusively demonstrate that subjects are capable of selective search of short, categorized lists. First, many of the existing effects can be accounted for by assuming that search is in fact serial and exhaustive, but that the comparison between a memorized item and a probe takes less time when the two items belong to different categories than when they belong to the same category. Such an assumption accounts naturally for the finding that the slope of the function relating RT to list length is small, but nonzero, when the probe and the list items differ in category (Lively \& Sanford, 1972; cf. Sternberg, 1975). Second, some puzzling failures to obtain evidence for selective search have been reported. Naus, Glucksberg, and Ornstein (1972) found that the slope of the RT function for probes of lists containing words in two semantic categories was reduced relative to probes of one-category lists, not by $50 \%$, as it should have been if subjects selectively searched just the items in the probed category, but by only $25 \%$, as if they constrained their search to the probed category just half the time (or as if the search rate for items not in the probed category was doubled). Darley (1973; also reported in Atkinson, Herrmann, \& Wescourt, 1974) similarly found evidence for imperfect selectivity of memory search. His subjects memorized lists factorially composed of zero to three digits and zero to three letters. Their RT increased by $40 \mathrm{msec}$ for each added memory item which was of the same class as the probe, and by $33 \mathrm{msec}$ for each added memory item which was of the different class. If search had been perfectly selective, RT should have been independent of the 
number of memory items which differed in class from the probe, at least in the range one to three.

Naus (1974) has appealed to the existence of strategies under the subject's control. She demonstrated that subjects could be trained in a selective search strategy, and that they would maintain such a strategy as long as the number of categories was large (four in number) relative to the length of the list. She argued that selective search was a strategy which cost time (in identify. ing the category of the probe and locating the proper category in memory), as well as saving time (by reducing the number of memorized items to be compared with the probe). In fact, the apparently successful demonstrations of selective search cited earlier used relatively large numbers of categories in the memorized lists and/or presented probes which could be rejected on the basis of category membership alone, both conditions which would make the selective search strategy more efficient.

Nonetheless, Darley's (1973) finding that subjects did not selectively search lists of letters and digits is surprising, in light of the apparent ease and speed with which subjects can categorize a probe item as a letter or a digit (Posner, 1970), or ignore letters or digits in a visual array when searching the array for an instance of the other class (Brand, 1971; Egeth, Jonides, \& Wall, 1972; Ingling, 1972; Jonides \& Gleitman, 1972). The present experiments represent a concerted attempt to provide evidence for selective search of lists of digits and letters. Well-practiced subjects memorized lists which contained two to five digits, or two to five letters, or two to five digits and two to five letters. They were given adequate study time on each list to allow them to organize the list into categories, and were tested for several trials on each list. Thus, the present experiments used a fixed set (Sternberg, 1966) procedure, unlike Darley's (1973) experiments, which used a varied set procedure. In two of the three experiments, there was natural correspondence between the letters presented in a list and the digits in the same list, to maintain comparability with some experiments on "translation" in memory scanning (Cruse \& Clifton, 1973; Clifton, Cruse, \& Gutschera, 1973), in which items in only one category were presented for memory but a positive probe could be a translation of a memorized item into the other category. However, the third experiment used an arbitrary correspondence between the letters and the digits in a list, and obtained results essentially the same as the first two experiments.

The RT data obtained were plotted as a function of the number of items in a single category. Selective search would be indicated by RT functions whose slopes were the same for two-category as for one-category lists. (The zero intercepts of the functions for two-category lists would be displaced upward by any time required to identify the category of the probe or to selectively access the items of the probe category.) An exhaustive search strategy, on the other hand, would be indicated by RT functions for two-category lists whose slopes were twice as great as those for one-category lists. ${ }^{2}$ (The zero intercepts would be greater for two-category than for one-category lists only if the time taken to encode a probe item is greater when its category is not known in advance than when its category is known.)

The present experiments further examined some sequential phenomena which might be expected to occur. Many researchers have noted effects of probe repetition in choice reaction time (cf. Kornblum, 1973) and in memory search (e.g., Biederman \& Stacy, 1974; Theios \& Walter, 1974), and other researchers have noted facilitation of responding when successive items come from the same category in memory search (e.g., Homa, 1973; Taylor \& Juola, 1974) and lexical decision (Meyer \& Schvaneveldt, 1971) tasks.

\section{EXPERIMENT I}

\section{Method}

Subjects. Five students at the University of Massachusetts were paid a minimum of $\$ 1.75$ a day, plus performance bonuses for each of 2 practice days and 4 experimental days. Prior to the first practice day, they were shown a list of letter-digit translations, $A=1, B=2, \ldots, I=9$, and were asked to memorize the list. Immediately before the first practice session, the experimenter informally tested the subject to make certain that he could recite the list errorlessly. Each day's session lasted approximately $1 \mathrm{~h}$, and each subject was tested individually or in the company of one other subject.

Procedure. On each day of the experiment, each subject received 16 blocks of 32 test trials. Each block began with a 30 -sec presentation on a computer-controlled video display of either a pure or a mixed list of items to be memorized. On four randomly selected trial blocks each day, the lists contained two to five randomly selected digits in the range 1 to 9 , one list of each length, and all probe items were digits (pure digit lists). On four blocks, the lists contained two to five letters from the set A-I, and the probes were letters (pure letter lists). On eight blocks, the lists contained two to five digits and two to five letters (mixed lists). In mixed lists, there was always the same number of digits and letters, and the letters presented were the memorized translations of the digits. The letters and digits were displayed in two horizontal rows, digits above letters, with a digit directly above its translation letter.

After offset of the list, 32 probe trials were given. On each trial, a single letter or digit probe was presented on a Burroughs B5871 alphanumeric NIXIE tube $400 \mathrm{msec}$ after a $100-\mathrm{msec}$ $500-\mathrm{Hz}$ warning tone. The subject was to pull a lever with his right forefinger if the probe was in the list memorized at the start of the block of trials, or a lever with his left forefinger it is was not. A correct response removed the probe item. Reaction time was measured to the nearest millisecond by a PDP-8/I computer. On each block of trials, 16 positive and 16 negative probes were presented, with the constraint that no more than four successive repetitions of one response could occur. On blocks testing mixed lists, half of the probes were digits and half were letters. In all experiments to be reported, negative probes were randomly selected from the items of the appropriate category which were used in the experiment, but which did not appear in the list currently being tested.

If the subject made an error, a button on his response console was illuminated, and he had to press it before the experiment continued. The time from a correct response or an error correc- 
Table 1

Error Percentages: Experiment 1

\begin{tabular}{lccrr}
\hline & \multicolumn{4}{c}{ List Length } \\
\cline { 2 - 5 } \multicolumn{1}{c}{ Condition } & 2 & 3 & 4 & 5 \\
\hline & \multicolumn{4}{c}{ Positive Probe } \\
Pure & 2.0 & 3.1 & 3.9 & 6.7 \\
Mixed, Class Repeat & 4.3 & 5.2 & 6.2 & 4.9 \\
Mixed, Class Nonrepeat & 5.6 & 5.5 & 5.7 & 10.0 \\
& & Negative Probe & \\
Pure & & 1.4 & 0.8 & 2.9 \\
Mixed, Class Repeat & 3.5 & 2.8 & 3.0 & 5.2 \\
Mixed, Class Nonrepeat & 2.2 & 7.0 & 5.4 & 8.7 \\
\hline
\end{tabular}

tion to the next probe was $2,500 \mathrm{msec}$. At the end of each trial block, the subject was given informative feedback about the number of errors he had made, his mean RT, and his bonus pay, which increased as a linear function of response speed and was decreased by 5 cents for each error. The subjects were instructed to keep their error rate below 5\% and to respond as quickly as possible.

Data analysis. Mean RTs were calculated separately for trials on which the probe was identical to the probe on the previous trial (or was a translation of that probe) and for trials on which it was different. Similarly, for mixed lists, mean RTs were calculated separately for trials on which the category (letter or digit) of the probe was the same as the category on the previous trial and for trials on which it was different. The former separation resulted in a post hoc experimental factor of item repetition-nonrepetition, while the latter separation resulted in the post hoc factor of class repetition-nonrepetition. (The item repetition factor was examined further by comparing probes which had one, two, or three or more other items intervening between repetitions, but these cases did not differ systematically and were combined in data analyses.)
Mean RTs for correct responses were calculated for each condition in the experiment, excluding RTs less than 200 or greater than $1,400 \mathrm{msec}$. Straight lines were fitted, using a least squares criterion, to each individual subject's data as a function of the number of letters, or the number of digits, in the memorized list for each experimental condition. Because item repetitions were relatively rare, there were no observations in a total of eight (out of 240) combinations of list length, condition, and subject for the item repetition subcondition. Estimates of RT were made for these combinations using an iterative technique described by Myers (1972) before fitting the straight lines. The slopes and zero intercepts of these fitted lines were subjected to analyses of variance with the following factors: Category condition (pure list, mixed list with class repetition of the probe; mixed list with class nonrepetition); Probe class (letter or digit); Response (positive or negative); Item (or translation) repetition-nonrepetition; and Subjects.

\section{Results}

Error rates. Table 1 displays the error percentages for each condition, collapsed over item repetitions and nonrepetitions (because of a limitation in the computer program which controlled the experiment). Error rates averaged $4.3 \%$ and were higher for probes of mixed lists, particularly class nonrepetition probes, than for probes of pure lists. Those conditions which will be shown to have the longer RTs are generally the conditions with higher error rates, permitting the rejection of the possibility that these longer RTs arose simply from a speed-accuracy tradeoff.

Reaction times. The mean correct RTs are shown in Figure 1, together with the slopes and intercepts of straight lines fitted (least squares) to these functions.
Figure 1. Reaction time as a function of the number of digits, or number of letters, in a list; Experiment I. Expressions adjacent to each line indicate RT (in milliseconds) as a function of list length, $L$.
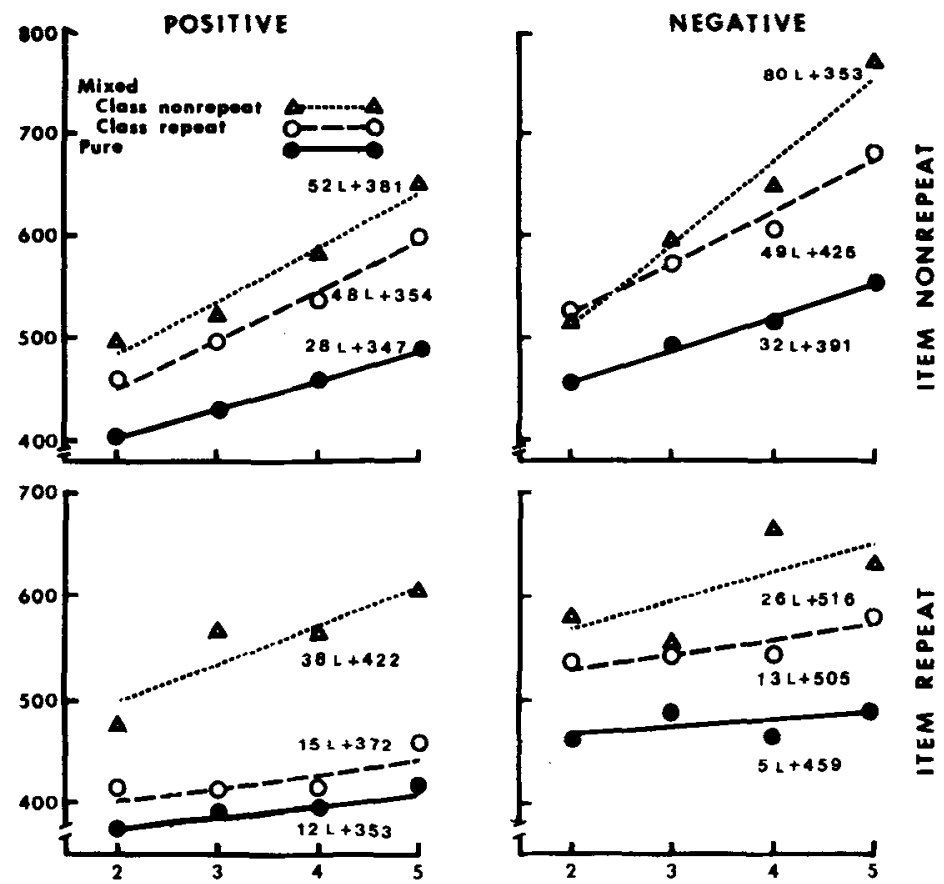

LIST LENGTH 
The squared coefficients of correlation between RT and list length, which may be interpreted as the percentage of variance among the mean RTs associated with the straight line, ranged from $96 \%$ to $99 \%$ for the item nonrepetition data, but were as low as $23 \%$ for the item repetition data.

The effect of Category condition (pure list, mixed list with class repetition, mixed list with class nonrepetition) upon slope was significant $[F(2,8)=16.39$, $\mathrm{MSe}=585, \mathrm{p}<.01]$. Considering just the item nonrepetition data, a Scheffé test indicated that the slope for the pure condition ( $30 \mathrm{msec} / \mathrm{item})$ was significantly $(p<.05)$ less than the slope for the mixed class repetition condition ( $48 \mathrm{msec} / \mathrm{item})$, which in turn was less than the slope for the mixed class nonrepetition condition ( $66 \mathrm{msec} / \mathrm{item})$. The zero intercepts of these three conditions did not differ significantly. The data are clearly inconsistent with a selective search process and, ignoring for the moment the effect of class repetitions, appear more consistent with the claim that a mixed list is searched exhaustively.

As noted above, class repetition probes resulted in flatter RT functions than class nonrepetition probes. In addition, item repetition probes yielded flatter functions than item nonrepetition probes, $18.7 \mathrm{vs} .48 .0 \mathrm{msec} /$ item $[\mathrm{F}(1,4)=56.58, \mathrm{MSe}=456, \mathrm{p}<.01]$, and higher zero intercepts, 440 vs. $375 \mathrm{msec}[F(1,4)=44.62$, $\mathrm{MSe}=2,847, \mathrm{p}<.01]$. The difference in both slopes and zero intercepts between item repetitions and nonrepetitions was greater for negative than for positive probes $[\mathrm{F}(1,4)=11.42, \mathrm{MSe}=284, \mathrm{p}<.05$ and $\mathrm{F}(1,4)$ $=10.91, \quad \mathrm{MSe}=4,916, \mathrm{p}<.05$, respectively $]$. The significance of the Item Repetition by Response by Category Condition interaction in the slope data $[\mathrm{F}(2,8)$ $=47.87, \mathrm{MSe}=29, \mathrm{p}<.01]$ reminds us that the item repetitions include data from class nonrepetitions, where an "item repetition" actually involved a probe which was a translation of the previous probe. Examination of Figure 1 indicates that the RT functions for repeated items are very flat indeed for pure lists and for class repetition probes of mixed lists, although their slope is significantly greater than zero, since the standard error of the slopes in Figure 1 is 1.70. The significance of this triple interaction also reflects the fact that the RT function for the class nonrepetition, negative probe condition was particularly steep for item nonrepetitions but not for item repetitions.

Two additional effects were significant. Digit probes resulted in steeper slopes and lower zero intercepts than letter probes $[F(1,4)=12.97, p<.05]$, but this effect was not observed in the later experiments. Also, the zero intercept for negative responses was greater than for positive responses $[F(1,4)=27.98, p<.01]$, but this effect was confounded with responding hand. Neither effect will be considered further.

\section{Discussion}

Considering just the item nonrepetition data, which best show the normally obtained linear increasing RT functions, there seems to be little or no evidence that subjects could selectively. search just that part of the memorized list which matched the probe in category. The slopes in the mixed list condition were approximately double the slopes in the pure list condition, as if subjects were comparing the probe against all memorized items of either category. However, this conclusion is qualified by the fact that the difference in slope between mixed and pure lists was greater for class nonrepetition than for class repetition. Experiments II and III were designed to replicate and explore this phenomenon.

Item repetition has been observed to speed RT in a memory search task (Biederman \& Stacy, 1974; Theios \& Walter, 1974) and the present data indicate that the effect is upon the slope of the function relating RT to list length. Such an effect may be interpretable in terms of the models proposed by Shiffrin and Schneider (1974). However, the fact that item repetition increased the zero intercepts of the RT functions has no ready explanation. It may deserve further study, especially since a similar effect seems to be present in Biederman and Stacey's (1974) data. The present data are too meager (as few as seven observations of item repetition RT in some cells of the present experimental design) to support further discussion of item repetition effects.

\section{EXPERIMENT II}

The second experiment was designed as a replication of the first, with some methodological refinements and with the addition of one experimental factor. The major methodological change was to test each subject on more, but shorter, blocks of trials each day, to reduce any confounding between experimental conditions and such factors as warm-up, fatigue, and particular list composition.

Although the primary purpose of Experiment II was to determine whether the effects noted in Experiment I were replicable, an attempt was made to specify the locus of the class repetition effect. Since this factor affected the slope of the RT function, the reasonable conclusion is that it acted upon the comparison stage, rather than upon some other stage. To confirm this conclusion, half of the lists were constructed of contiguous letters or digits (e.g., 2-3-4 or B-C-D), while half were constructed of randomly selected letters or digits. Some experimenters (Egeth, Marcus, \& Beven, 1972; Clifton, Cruse, \& Gutschera, Note 1; Clifton, Cruse, Gutschera, \& Torosian, Note 2) have reported faster scanning rates for contiguous than for noncontiguous lists, indicating that the effect of list contiguity was on the comparison stage. Following the logic of Sternberg (1969b), if the effect of class repetitionnonrepetition is on the comparison stage, one would expect to obtain an interaction between contiguous vs. noncontiguous lists and class repetition-nonrepetition. If the effect of contiguous lists is to increase the search 

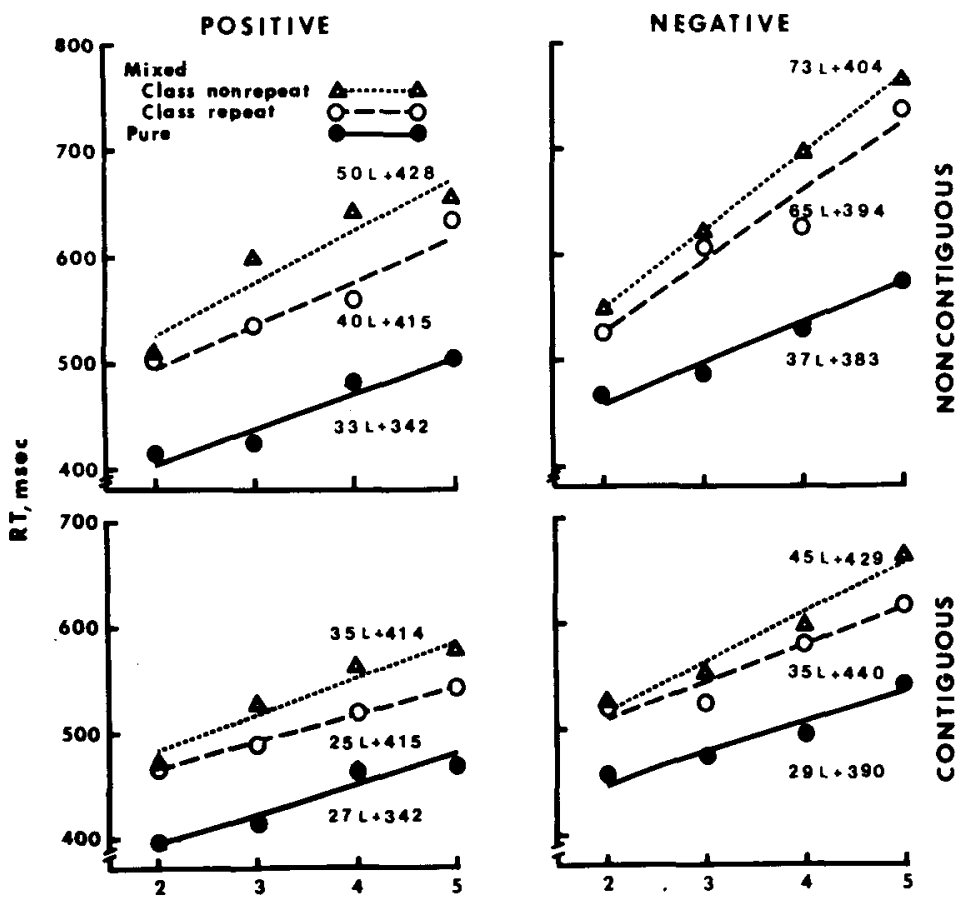

Figure 2. Reaction time as a function of the number of digits, or number of letters, in a list; Experiment II. Expressions adjacent to each line indicate RT (in milli-

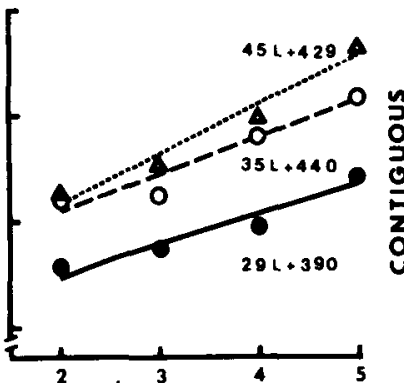
seconds) as a function of list length, $L$.

LIST LENGTH

rate, then the obtained effect of class repetitionnonrepetition should be smaller for contiguous than for noncontiguous lists. A stronger hypothesis is that a mixed contiguous list is more easily categorized as two chunks and that clear evidence of selective search would be obtained for contiguous lists.

\section{Method}

Each of seven subjects was tested for 1 practice day and 4 experimental days. The procedure was generally the same as in Experiment I, except that 32 lists of two to five letters, two to five digits, or two to five letters and two to five digits were presented each day, and each list was tested with 16 probes. In addition, half of the lists within each condition were composed of letters and/or digits which were contiguous in the alphabet or the number series, while half of the lists were composed of randomly chosen letters and/or digits. As before, the letters and digits in mixed lists were previously learned translations of each, $A=1, B=2$, etc. One constraint upon probe sequences was changed: No more than three (rather than four, as in Experiment I) successive occurrences of the same response were allowed.

\section{Results}

The error rate, averaged across all noncontiguous conditions, was $3.5 \%$, and was $2.5 \%$ averaged across all contiguous conditions. The pattern of error rates across set sizes and across category conditions was generally similar to that found in Experiment I.

Reaction times were analyzed as in Experiment I, except that RTs to item repetition probes were eliminated. They were not analyzed separately because of their extreme rarity, resulting from the constraint on response sequences. The means of the remaining RTs are presented in Figure 2, with the straight lines fitted to these functions. Analyses of variance were performed on the slopes and zero intercepts of straight lines fitted to individual subject's RTs. The analyses had the same factors as in Experiment I, except that list structure (contiguous vs. noncontiguous) replaced item repetitionnonrepetition.

As in Experiment I, the effect of Category condition upon slopes was significant $[F(2,12)=11.94, \mathrm{MSe}=438$, $\mathrm{p}<.01]$. Probes of pure lists produced the RT functions with the smallest slopes $(31.3 \mathrm{msec} / \mathrm{item})$, while the slopes for category repetition and category nonrepetition probes of mixed lists were significantly higher (41.5 and $50.6 \mathrm{msec} / \mathrm{item}$, respectively; $\mathrm{p}<.05$, Scheffé test). The latter two slopes differed from each other at the .10 level of significance. The interaction of Response by Category Condition reached statistical significance in neither the analysis of slopes nor of intercepts. The deviantly steep negative class nonrepetition function observed in Experiment I was not obtained in Experiment II. However, two effects were significant in Experiment II which were nonsignificant in Experiment I. The RT functions for negative probes were steeper than those for positive probes, 47.2 vs. $35.0 \mathrm{msec} /$ item $[F(1,6)=33.58, M S e=187, p<.01]$, and the zero intercept for the pure list condition $(364 \mathrm{msec}$ ) was lower than those for both class repetition and class nonrepetition probes of mixed lists $(416$ and $418 \mathrm{msec}$, respectively) $[F(2,12)=11.05, \mathrm{MSe}=4,783, \mathrm{p}<.01]$.

Contiguous lists produced smaller slopes than noncontiguous lists, 32.5 vs. $49.7 \mathrm{msec} /$ item $[F(1,6)=$ $18.62, \mathrm{MSe}=664, \mathrm{p}<.01 \mathrm{]}$, indicating that the effect of contiguous vs. noncontiguous list was upon the memory comparison stage. However, the interaction of Contiguous vs. Noncontiguous List by Class Repetition vs. Class Nonrepetition, which would indicate that the 
effect of the latter variable was also upon the memory comparison stage, was not significant. The effect of class repetition (the difference in slope between class repetition and class nonrepetition probes) was $9.9 \mathrm{msec} /$ item for contiguous lists and $8.4 \mathrm{msec} / \mathrm{item}$ for noncontiguous lists.

It is interesting to note, however, that the slopes for class repetition probes of contiguous lists were very similar to the slopes for probes of pure contiguous lists, 30 vs. $28 \mathrm{msec} /$ item, as if subjects were able to constrain their search in the former case to items of the same category as the probe. Further, the slopes for class nonrepetition probes of contiguous lists were less than twice the slopes for probes of pure contiguous lists, as if subjects did not always search all presented items in deciding about a class nonrepetition probe of a contiguous list but were sometimes able to search such a list selectively. It is possible that subjects followed different memory search strategies for contiguous and noncontiguous mixed lists. If this is so, then the prediction that class repetition and list contiguity will interact does not necessarily follow from the assumption that class repetition affects the memory comparison stage. Thus, Experiment II does not allow such an assumption to be rejected.

\section{EXPERIMENT III}

The primary conclusions from Experiment II concur with those of Experiment I: For lists of randomly chosen digits and letters, there is no evidence that subjects could selectively scan just those items which matched the probe in class. The failure to find such evidence is sufficiently surprising to justify a further attempt to find a condition under which subjects are able to examine a selected portion of the contents of memory. One condition which some experimenters have found effective in facilitating such a selective search is to inform their subjects of the category of the probe before its occurrence. Kaminsky and DeRosa (1972) found that a cue presented 2 sec before a digit or a letter probe allowed their subjects to constrain their search, at least in part, to the memorized items of the same category as the probe. Okada and Burrows (1973) and Crain and DeRosa (1974) have reported similar effects for other classes of materials, and Naus (1974) informed her subjects of the probe category $.8 \mathrm{sec}$ before the probe was presented when she successfully trained them to use a selective search strategy. Krueger's (1975) subjects (at least late in training) seemed to be able to constrain their search to the proper one of two lists, one of letters and the other of digits, in a task in which the category of the probe was perfectly predictable.

Subjects in all of these studies [except Naus' (1974)] knew the category of the probe in advance and could rehearse the items in the to-be-probed category; in the
Kaminsky and DeRosa (1972) experiment, they were allowed to forget the noncued items. Experiment III used precue intervals which should be too short to allow effective list rehearsal. However, Naus' (1974) analysis of selective search in terms of its efficiency as a strategy (discussed earlier) indicated that the time required to identify a probe category and to access the proper category in memory was approximately $200 \mathrm{msec}$. The intervals used in Experiment III were long enough to allow such category identification and access to take place, and, thus, under the argument of strategy efficiency, were long enough to allow selective search to occur.

\section{Method}

Eight students and faculty were tested for two 1 h practice sessions and four experimental sessions. They had not been pretrained in a letter-digit correspondence scheme, since Experiment III was intended to determine whether the results reported in the earlier experiments held when the correspondence between letters and digits in a mixed list was not natural. Subjects received 36 blocks of 16 trials each on each day. Eighteen of the blocks began with the presentation of a mixed list of two to four randomly chosen digits and two to four letters. Whenever the digit member of one of the following pairs appeared in a list, the corresponding letter appeared below it: $0=X, 1=C$, $2=\mathrm{P}, 3=\mathrm{K}, 4=\mathrm{L}, 5=\mathrm{N}, 6=\mathrm{R}, 7=\mathrm{D}, 8=\mathrm{T}$, and $9=\mathrm{B}$. Nine of the blocks began with the presentation of a pure list of two to four digits in the range 0 to 9 , and nine began with the presentation of a pure list of two to four letters selected from those above. The list was displayed until the subject pressed a "ready" button, to insure that he had adequate time to organize the list in memory.

Positive and negative probes were presented so that 16 of each occurred in Blocks 1 and 2, 16 in Blocks 3 and 4, etc. with the constraint that no more than three contiguous occurrences of one response were allowed. On blocks testing mixed lists, half of the probes were digits and half were letters, while all probes testing pure lists were of the same form as the list. Onset of a $100-\mathrm{msec}$ warning tone preceded the display of the probe item by either 450 or $800 \mathrm{msec}$. On tests of mixed lists, the tone was either informative as to the category of the forthcoming probe $(1,200 \mathrm{~Hz}$ preceding a letter probe, $100 \mathrm{~Hz}$ preceding a digit probe for four subjects, vice versa for four subjects) or noninformative $(300 \mathrm{~Hz})$. Each type and delay of cue occurred equally often with each type of probe. The $300-\mathrm{Hz}$ cue was always used for tests of pure lists, but a randomly selected half of the tones were designated "informative" to create a dummy variable which maintained the orthogonality of the experimental design. Subjects responded and received feedback as in the earlier experiments, except that they received a point score rather than bonus payments for good performance.

\section{Results}

Error rate was uniformly low, averaging $2.7 \%$. Errors and RTs less than 200 or greater than $1,400 \mathrm{msec}$ were eliminated from the data. Because of a limitation in the computer program which controlled the experiment, it was not possible to separate item repetitions from item nonrepetitions. However, because item repetitions were infrequent, as in Experiment II, and because generally similar effects occurred in the first two experiments whether all data or only item nonrepetitions were considered, it was thought that this shortcoming would not seriously compromise the analysis. 
The functions relating mean RT to list length, collapsed over cue delay, appear in Figure 3, and the parameters of the straight lines fitted to them (not so collapsed) appear in Table 2. Analyses of variance with the factors used previously, plus the factors of cue informativeness and cue delay, were performed on the slopes and zero intercepts of straight lines fitted to each individual subject's data:

The effect of Category condition upon slopes was significant, as in the previous experiments $[\mathrm{F}(2,14)=$ $10.88, \mathrm{MSe}=2,897, \mathrm{p}<.01]$. A Scheffé test indicated that the RT function was steeper for class nonrepetition probes of mixed lists $(58.3 \mathrm{msec} /$ item $)$ than for class repetition probes of mixed lists $(39.2 \mathrm{msec} / \mathrm{item}$, $\mathrm{p}<.10)$ or for probes for pure lists $(27.2 \mathrm{msec} / \mathrm{item}$, $p<.05)$. The difference between the latter two slopes did not reach an acceptable level of significance. The effect of cue informativeness upon slopes was thoroughly nonsignificant $[\mathrm{F}(1,7)=.09$, MSe $=1,449]$, as was the interaction of Cue Informativeness by Category Condition $[\mathrm{F}(2,14)=.05, \mathrm{MSe}=694]$. The negative functions were steeper than the positive functions at the long cue delay, but not at the short $[F(1,7)=5.68$, $\mathrm{MSe}=707, \mathrm{p}<.05]$.

Quite different results were obtained for the zero intercepts. Here, the interaction of Cue Informativness by Category Conditions was significant $[\mathrm{F}(2,14)=6.33$, $\mathrm{MSe}=4,523, \mathrm{p}<.05]$. The zero intercepts for class repetition and class nonrepetition probes of mixed lists in the noninformative cue condition did not differ from each other (392 and $399 \mathrm{msec}$ ), but were significantly greater $(\mathrm{p}<.10$, Scheffé test) than the zero intercepts for pure lists $(352 \mathrm{msec})$ or for class repetition and class nonrepetition probes of mixed lists in the informative cue condition ( 362 and $342 \mathrm{msec}$ ). Differences

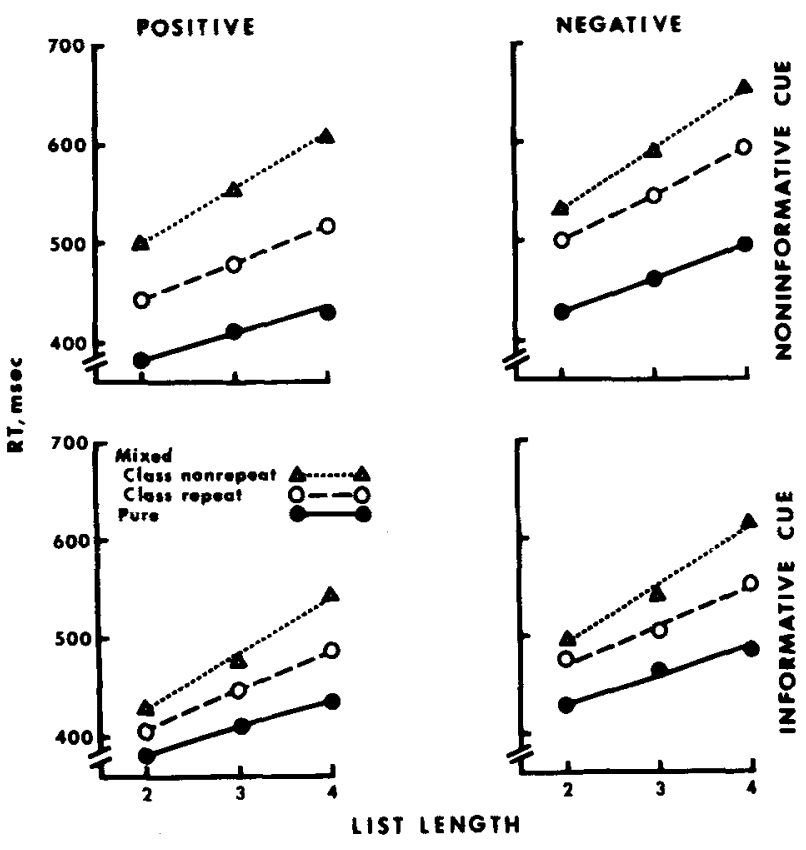

Figure 3. Reaction time as a function of the number of digits, or number of letters, in a list; Experiment III.

among these latter three intercepts were nonsignificant. Thus, providing an informative cue lowered the zero intercepts of the RT functions for probes of mixed lists, to the point where they were the same as for pure lists. In addition, zero intercepts were higher following a 450-msec than an 800-msec cue delay, especially for negative probes $[\mathrm{F}(1,7)=8.28, \mathrm{MSe}=1,295, \mathrm{p}<.05]$, but this difference may indicate merely level of general preparedness, since it did not interact with any other factor.

Table 2

Parameters of Straight Lines Fitted to Mean RTs: Experiment III

\begin{tabular}{|c|c|c|c|c|c|c|c|}
\hline \multirow[b]{2}{*}{ Condition } & \multirow[b]{2}{*}{ Delay } & \multicolumn{6}{|c|}{ Response } \\
\hline & & Slope & $\begin{array}{c}\text { Positive } \\
\text { Intercept }\end{array}$ & $\%$ Var & Slope & $\begin{array}{l}\text { Negative } \\
\text { Intercept }\end{array}$ & $\% \mathrm{Var}$ \\
\hline & \multicolumn{7}{|c|}{ Noninformative Cue } \\
\hline Pure & $\begin{array}{l}\text { Short } \\
\text { Long }\end{array}$ & $\begin{array}{l}25.0 \\
23.5\end{array}$ & $\begin{array}{l}335 \\
334\end{array}$ & $\begin{array}{l}99 \\
99\end{array}$ & $\begin{array}{l}28.0 \\
35.0\end{array}$ & $\begin{array}{l}380 \\
351\end{array}$ & $\begin{array}{l}99 \\
99\end{array}$ \\
\hline Mixed, Class Repeat & $\begin{array}{l}\text { Short } \\
\text { Long }\end{array}$ & $\begin{array}{l}35.0 \\
33.0\end{array}$ & $\begin{array}{l}373 \\
381\end{array}$ & $\begin{array}{r}99 \\
100\end{array}$ & $\begin{array}{l}39.0 \\
53.0\end{array}$ & $\begin{array}{l}430 \\
382\end{array}$ & $\begin{array}{l}99 \\
98\end{array}$ \\
\hline \multirow[t]{2}{*}{ Mixed, Class Nonrepeat } & $\begin{array}{l}\text { Short } \\
\text { Long }\end{array}$ & $\begin{array}{l}55.5 \\
54.5\end{array}$ & $\begin{array}{l}396 \\
385\end{array}$ & $\begin{array}{l}99 \\
99\end{array}$ & $\begin{array}{l}56.0 \\
66.5\end{array}$ & $\begin{array}{l}427 \\
386\end{array}$ & $\begin{array}{l}99 \\
99\end{array}$ \\
\hline & \multicolumn{7}{|c|}{ Informative Cue } \\
\hline Pure & $\begin{array}{l}\text { Short } \\
\text { Long }\end{array}$ & $\begin{array}{l}25.0 \\
25.5\end{array}$ & $\begin{array}{l}332 \\
331\end{array}$ & $\begin{array}{l}99 \\
99\end{array}$ & $\begin{array}{l}28.5 \\
26.5\end{array}$ & $\begin{array}{l}378 \\
371\end{array}$ & $\begin{array}{l}98 \\
98\end{array}$ \\
\hline Mixed, Class Repeat & $\begin{array}{l}\text { Short } \\
\text { Long }\end{array}$ & $\begin{array}{l}35.5 \\
38.5\end{array}$ & $\begin{array}{l}346 \\
320\end{array}$ & $\begin{array}{l}99 \\
99\end{array}$ & $\begin{array}{l}33.0 \\
46.0\end{array}$ & $\begin{array}{l}424 \\
357\end{array}$ & $\begin{array}{l}95 \\
98\end{array}$ \\
\hline Mixed, Class Nonrepeat & $\begin{array}{l}\text { Short } \\
\text { Long }\end{array}$ & $\begin{array}{l}61.0 \\
53.0\end{array}$ & $\begin{array}{l}324 \\
300\end{array}$ & $\begin{array}{l}97 \\
99\end{array}$ & $\begin{array}{l}69.0 \\
50.0\end{array}$ & $\begin{array}{l}364 \\
380\end{array}$ & $\begin{array}{l}98 \\
99\end{array}$ \\
\hline
\end{tabular}


There were several uninterpretable interactions in both analyses between Probe (digit vs. letter) and Delay, Condition, Cue Informativeness, and Response. Examination of the RT data indicated that the interactions might reflect nothing more than a deviantly high mean RT for digits in one of the List Length 4 conditions, and one for letters in a different List Length 4 condition.

\section{Discussion}

Providing a cue which informs the subject of the category of a probe item either 450 or $800 \mathrm{msec}$ before the probe is presented did not enable him to restrict his search of memory to items of the same category as the probe. The informative cue did decrease the zero intercepts of the mixed list RT functions by $43 \mathrm{msec}$, indicating that subjects did use the cue in some manner. However, the informative cue did not affect the slope of the RT functions, which argues against the possibility that the cue acted upon the memory comparison process. Since an informative cue affected both positive and negative RTs, a model (e.g., Shiffrin and Schneider, 1974) which suggests that subjects expect a single item as a probe and encode an expected item faster than an unexpected one seems inadequate. Rather, an informative cue seems to facilitate the identification of any member of the cued category.

Marcel and Forrin (1974) provide support for this interpretation. In a task in which the subject was to name digits and letters, precueing him as to the category of the next test item $1 \mathrm{sec}$ before its presentation decreased naming time by approximately $40 \mathrm{msec}$. Marcel and Forrin did not obtain such an effect when the precue was presented $500 \mathrm{msec}$ before the test item, although a precue $450 \mathrm{msec}$ before the probe was adequate for the highly practiced subjects used in the present experiment.

As in Experiments I and II, repeating the category of the probe of a mixed list reduced the slope of the RT functions of Experiment III. Such an effect is more naturally interpreted in terms of a change in the memory comparison process. Interestingly, Marcel and Forrin (1974) found that repeating the category of an item on naming trials $1.5 \mathrm{sec}$ apart also decreased naming time by approximately $40 \mathrm{msec}$. Since they found that category repetition had no effect when subjects were given a correct category precue, they suggested that category repetition and category precue affected identification time through the same mechanism (and suggested that the mechanism probably involved priming, or activating, the memory representations of the members of a category). However, the present data make it clear that repeating a category and precueing a category affect different stages in an item recognition task, since the former affected the slopes and the latter the zero intercepts of the RT functions, and since the effect of each variable was independent of the level of the other variable. The resolution of this disagreement in interpretation probably lies in an unidentified differ- ence between the item naming and item recognition tasks. It may be that the former task does not correspond to a substage of the latter task, or it may be that some characteristic of the item recognition task (involving, perhaps, the subject's tendency to rehearse between trials) changes the nature of the category repetition effect.

\section{CONCLUSIONS}

The experiments reported here tested the hypothesis that subjects could selectively scan either the letters or the digits of a memorized mixed list of letters and digits. The results were consistent with available evidence (Atkinson, Herrmann, \& Wescourt, 1974; Kaminsky \& DeRosa, 1972) that subjects cannot do so under conditions in which both classes of items can be assumed to be present in active memory, except possibly when the probed list contains only contiguous items. When a probe presented on one trial differed in category from the probe presented on the previous trial, the slope of the function relating RT to the number of items in one category of a mixed list was approximately twice the slope of the function for lists which contained only a single category, indicating that the mixed list was exhaustively scanned. When a probe of a mixed list was of the same category as the previous probe, the slope of the RT function was reduced, a finding which will be discussed below.

The present experiments do not explain the difference between the apparent ease of using category information in visual search (Egeth, Jonides, \& Wall, 1972 ) and the difficulty of using such information in memory search. There are numerous differences between the visual search and memory search tasks, as they have been studied. One difference (cf. Digman \& Pollatsek, Note 3; Posner, Note 4) is that the memory search task requires identification of the specific probe item, while the visual search task requires identification of only its category. Such a difference could be relevant if subjects can categorize a probe without determining its specific identity. Another difference, perhaps even more basic, is that the category effect in visual search may depend upon subjects being highly practiced in a consistent stimulus-response relationship. Schneider (Note 5, Experiment 13) found that the category effect disappeared when subjects who were practiced in responding to the presence of a digit in a visual display were shifted to responding to the presence of a letter (or vice versa).

Still, there do seem to be cases in which subjects can perform an effective selective search of memory. Naus (1974) found selective memory search when the number of categories was large, relative to the number of items, and suggested that subjects searched selectively in this case because the savings in search time were large relative to the presumed time to extract and use information about the category of the probe item. One 
finding of the present Experiment III may speak to this latter suggestion. Precueing the subject about the category of the probe up to $.8 \mathrm{sec}$ before the probe is presented does not seem to affect memory search, although $.8 \mathrm{sec}$ is far greater than the time identification of the probe category and access of the properly categorized items in memory can take if this analysis is to account for Naus' (1974) data. One apparently must conclude either that category information provided by a precue cannot be used as efficiently as category information provided by a probe, or that the analysis of Naus' selective search in terms of time costs and savings is incorrect.

The novel finding of the present research is the difference in slopes between class repetition and class nonrepetition probes of mixed lists. ${ }^{3}$ Had probes of mixed lists not been separated into class repetition and class nonrepetition, the present experiments would have obtained the typical finding that the number of items in the nonprobed category has some influence on RT, but less than the number of items in the probed category has (Darley, 1973; cf. Lively \& Sanford, 1972; Naus, Glucksberg, \& Ornstein, 1972). The different results obtained for class repetition and class nonrepetition probes may allow us to assess some of the accounts that have been offered for this latter finding.

One account is simply that decisions that a probe item is different from a remembered item are made faster when the items differ in category than when they do not. This suggestion does not seem to provide an account of the category repetition effect observed here. First, it would seem to claim that the RT function for class nonrepetition probes of mixed lists would be less than twice as steep as the function for probes of pure lists, since half the items being compared in the former case differ in category from the probe. Second, the suggestion would have to account for the difference in slope between class repetition and class nonrepetition probes of mixed lists by saying that categorybased decisions that a probe item differs from a memory item would be facilitated if an item of the class of the memory item had not just previously been probed, an unappealing assumption.

A second account of the previously reported finding that items different in class from the probe have a smaller effect on RT than items which are the same in class would claim that memory search is, in fact, selective, but that the memorized items that differ in class from the probe constitute a memory load which uses processing capacity, thus increasing RT. Such an account can handle the finding that the number of extra-category items has a linear effect on RT only in an ad hoc way; it does not account for the class repetition effect; it seems to be contradicted by experiments in which effective selective search does occur (e.g., Mohs, Wescourt, \& Atkinson, 1973); and it has been disconfirmed by direct tests (Darley, Klatzy, \& Atkinson, 1972; Wattenbarger \& Pachella, 1972).
A third account (cf. Mohs, Wescourt, \& Atkinson, 1973) suggests that two serial searches take place in parallel, one of the last-probed category and one of the other category, the latter at half the rate at which a simple noncategorized list is searched and the former somewhat faster. A decision about a probe item is made as soon as the search of the appropriate category is completed. While this process could account for the data presented here, it cannot account for the findings of Darley (1973) (Atkinson, Herrmann, \& Wescourt, 1974). Darley factorially manipulated the number of letters and the number of digits in memorized lists, and found an additive effect of the number of items in both classes on R'T. The parallel searches account sketched here would have to predict that RT to a probe item would be a function of only the number of memorized items of the same class as the probe.

The most adequate account of the available data is that offered by Naus, Glucksberg, and Ornstein (1972), modified in two ways. Naus et al. suggested that subjects store items from two different categories in separate sublists, and randomly access one category when a probe is presented. They exhaustively compare the probe with the members of the accessed category, at the same time deciding whether the probe belongs to the accessed category. If it does, the response is made when the search of the accessed category is completed. Otherwise, the same process is performed on the other memorized category.

The first modification of this model required by the present data is to suggest that subjects do not randomly access one category for comparison with the probe, but instead first access the category which was probed on the previous trial. Thus, when a probe differs in category from the previous probe, all items in both categories would have to be searched. Such a process is consistent with the observation of the present experiments that the slope of the RT function for class nonrepetition probes of mixed lists was approximately double that for probes of pure lists.

The second modification is required by the fact that the slope for class repetition probes of mixed lists was not the same as for probes of pure lists, as it should have been if subjects perfectly constrained their search to the last-probed category. The suggestion to be made here is that, for mixed lists of letters and digits (but possibly not for the semantic categories of girls' names and animals that Naus et al. used), subjects do not always respond upon completing the search of the first-searched category when it matches the probe category, but sometimes (with probability $1-p$ ) scan the other category in addition. ${ }^{4}$

According to this model, RT should be described by the following equations:

$$
\begin{array}{ll}
\mathrm{RT}_{\text {pure }} & =\mathrm{A}+\mathrm{BS} \\
\mathrm{RT}_{\text {mixed nonrepeat }} & =\mathrm{A}^{\prime}+\mathrm{B}\left(\mathrm{S}_{1}+\mathrm{S}_{2}\right)
\end{array}
$$


Table 3

Predicted and Observed Slopes, and Parameter Values: All Experiments

\begin{tabular}{lcccccc} 
& & \multicolumn{4}{c}{ Experiment } \\
\cline { 3 - 6 } \multicolumn{1}{c}{ Value } & pred & obs & pred & obs & pred & obs \\
\hline Pure & 32.4 & 30.1 & 31.4 & 34.8 & 28.7 & 27.1 \\
Mixed Nonrepeat & 64.8 & 66.0 & 62.8 & 61.2 & 57.4 & 58.3 \\
Mixed Repeat & 47.9 & 48.1 & 53.1 & 53.0 & 39.0 & 39.1 \\
B & 32.4 & & 31.4 & 28.7 \\
p & & .54 & & .31 & & .64 \\
\hline
\end{tabular}

$\mathrm{RT}_{\text {mixed repeat }}=\mathrm{A}^{\prime}+\mathrm{pBS}_{1}+(1-\mathrm{p}) \mathrm{B}\left(\mathrm{S}_{1}+\mathrm{S}_{2}\right)$,

where $p$ is the probability that a response is made after searching only a category, $A$ is the encoding and response time for pure lists, $A^{\prime}$ the encoding and response time for mixed lists, B the time taken to compare the probe against one list item, $S$ the number of items in a pure list, $S_{1}$ the number of items in the probed category of a mixed list, and $S_{2}$ the number of items in the nonprobed category. In the present experiments, $\mathrm{S}=\mathrm{S}_{1}=\mathrm{S}_{2}$ and $\mathrm{A}^{\prime}=\mathrm{A}$ when the subject is precued for the category of the probe.

Following these formulas, the slope of the function relating RT to $\mathrm{S}$ would be B for probes of pure lists, $2 \mathrm{~B}$ for class nonrepetition probes of mixed lists, and $(2-p) B$ for class repetition probes of mixed lists. The predicted and observed slopes for each experiment (averaged over responses and other conditions but discarding the item repetition data from Experiment I and the contiguous list data for Experiment II) and the least squares estimates of the parameters appear in Table 3. The model can also be fit to the data of Darley (1973), who factorially varied $S_{1}$ and $S_{2}$ and used a varied set procedure, if one assumes that the probe matched the first-accessed category $50 \%$ of the time. When $\mathrm{p}$ is estimated to be .35 , the model provides data fits identical to those reported by Atkinson, Herrmann, \& Wescourt (1974).

While the model does fit the bulk of the data presented, some of its assumptions need further exploration. Particularly questionable is the assumption that RTs to class repetition probes arise from a mixture of two different processes, one in which $\mathbf{S}$ items are searched and one in which $2 S$ items are searched. If this assumption is correct, properties of the class repetition RT distribution should be predictable from estimates of distributions in which $\mathrm{S}$ and $2 \mathrm{~S}$ items are searched (similar to what Naus et al., 1972, did in predicting variances of RTs to probes of mixed lists from variances and means of RTs to probes of pure lists). Unfortunately, adequate estimates of the distributions for searches of $S$ and of $2 S$ items are not available in the present experiments. However, variances predicted on the basis of the most adequate estimates (the distributions for probes of pure lists, and for class non- repetition probes of mixed lists, for searches of $S$ and $2 S$ items, respectively) were consistently greater than the obtained variances of RTs to class repetition probes, providing some equivocal evidence against the assumption.

Setting aside such concerns, the present data and their theoretical interpretation suggest some interesting generalizations. First, selective search of even such easily categorized materials as letters and digits is not the rule. Second, the factor preventing such selective search is not merely the several hundred milliseconds which would be required to identify the category of the probe item (as was indicated by the failure of the precues used in Experiment IIl to modify the search process). Finally, recent testing of a category modifies the availability of items from that category, perhaps by changing the sequence in which the contents of memory are searched.

\section{REFERENCE NOTES}

1. Clifton, C., Jr., Cruse, D., \& Gutschera, K. D. On the interaction of target set and response requirement in a character classification task. Report 73-2, Cognitive Processes Laboratory, Department of Psychology, University of Massachusetts, Amherst. March 1973.

2. Clifton, C., Jr., Cruse, D., Gutschera, K. D., \& Torosian, S. The lack of interaction between target set and response requirement in a character classification task. Report 75-2, Cognitive Processes Laboratory, Department of Psychology, University of Massachusetts. Amherst, June 1975.

3. Digman, L., \& Pollatsek, A. Limits on the use of categorical information in visual search. Unpublished manuscript, 1975.

4. Posner, M. Personal communication, September 23, 1975.

5. Schneider, W. Selective attention, memory scanning, and visual search: Three components of one process. Report 75-6, Indiana Mathematical Psychology Program, Indiana University, 1975.

\section{REFERENCES}

Atrinson, R. C., Herrmann, D. J., \& Wescourt, K. T Search processes in recognition memory. In $R$. L. Solso (Ed.), Theories in cognitive psychology. Washington, D.C: Winston, 1974

BARRON, R. W. Locus of the effect of a distinguishing feature in a memory search task. Memory \& Cognition, 1975, 3, $302-310$

Biederman, I., \& Stacy, E. W. Stimulus probability and stimulus set in memory scanning. Journal of Experimental Psychology, 1974, 102, 1100-1107.

Brand, J. Classification without identification in visual search. Quarterly Joumal of Experimental Psychology, 1971, 23, 178-186.

Clifton, C., Jr., Cruse, D.. \& Gutschera, K. D. Recoding processes in recognition: Some effects of presentation rate. Memory \& Cognition, 1973, 1, 387-394.

Clifton, C., JR., \& Gutschera, K. D. Hierarchical search of two-digit numbers in a recognition memory task. Journal of Verbal Learning and Verbal Behavior, 1971, 10, 528-542.

Crain, R. D., \& DeRosa, D. V. Retrieval of information from multiple ensembles in short-term memory. Memory \& Cognition, 1974, 2, 255-260.

CRUSE, D., \& Clifton, C., JR. Recoding strategies and the retrieval of information from memory. Cognitive Psychology,
$1973,4,157-193$. 
DARLEY. C. F. Effects of memory load and its organization on the processing of information in short term memory. (Doctoral dissertation, Stanford University, 1973). Dissertation Abstracts International, 1974, 34, G234B. (University Microfilms No. 74-13,618).

Darley, C. F., Klatzky, R. L., \& Atrinson, R. C. Effects of memory load on reaction time. Joumal of Experimental Psychology, 1972, 96, 232-234.

Egeth, H., Jonides, J., \& Wall, S. Parallel processing of multi-element displays. Cognitive Psychology, 1972, 3, 674-698.

Egeth. H., Marcus, N., \& Bevan, W. Target-set and response-set interaction: Implications for models of human information processing. Science, 1972, 176, 1447-1448.

Herrmann, D. J., Mclaughis, J. P., \& Nelson, B. C. Visual and semantic factors in recognition from long-term memory. Memory \& Cognition, 1975, 3, 381-384.

НомА, D. Organization and long-term memory search. Memory \& Cognition, 1973, 1, 369-379.

INGLING, N. W. Categorization: A mechanism for tapid information processing. Journal of Experimental Psychology, 1972, 94, 239-243.

Jonides, J., \& Gleitman, H. A conceptual category effect in visual search: $O$ as letter or digit. Perception \& Psychophysics, $1972,12,457-460$.

Kaminsky, C. A., \& DeRosa, D. V. Influence of retrieval cues and set organization on short-term recognition memory. Journal of Experimental Psychology, 1972, 96, 449-454.

Kornblum, S. Sequential effects in choice reaction time: A tutorial review. In S. Kornblum (Ed.), Attention and performance IV. New York: Academic Press, 1973.

KRUEGER, L. T. The effect of an extraneous added memory set on item recognition: A test of parallel-dependent vs. serial-comparison models. Memory \& Cognition, 1975, 3, 485-495.

LuVely, B. L., \& SANford, B. J. The use of category information in a memory-search task. Joumal of Experimental Psychology, 1972, 93, 379-385.

Marcel, T., \& Forrin, B. Naming latency and the repetition of stimulus categories. Journal of Experimental Psychology, 1974, 103, 450-460.

Meyer, D. E., \& Schvaneveldt, R. W. Facilitation in recognizing pairs of words: Evidence of a dependence between retrieval operations. Journal of Experimental Psychology, 1971, 90, 227-234.

Mohs, R. C., Wescourt, K. T., \& Atrinson, R. C. Effects of short-term memory contents on short- and long-term memory searches. Memory \& Cognition, 1973, 1, 443-448.

MYERS, J. L. Fundamentals of experimental design. Boston: Allyn and Bacon, 1972.

NAus, M. J. Memory search of categorized lists: A consideration of alternative self-terminating search strategies. Journal of Experimental Psychology, 1974, 102, 992-1000.

Naus, M. J., Glucksberg, S., \& Ornstein, P. A. Taxonomic word categories and memory search. Cognitive Psychology, $1972,3,643-654$.

OKADA, R., \& Burrows, D. Organizational factors in highspeed scanning. Journal of Experimental Psychology, 1973, 101, 77.81.

Posner, M. I. On the relationship between letter names and superordinate categories. Quarterly Joumal of Experimental Psychology, 1970, 22, 279-287.

Shiffris, R. M., \& Schneider, W. An expectancy model for memory search. Memory \& Cognition, 1974, 2, 616-628.

Sternberg, S. High-speed scanning in human memory. Science, 1966, 153, 652-654.

Sternoerg, S. Memory-scanning: Mental processes revealed by reaction-time experiments. American Scientist, 1969, 57, 421-457. (a)
STERnBerG, S. The discovery of processing stages: Extensions of Donder's method. In W. G. Koster (Ed.), Attention and performance II. Amsterdam: North-Holland, 1969. (b)

Sternberg. S. Memory scanning: New findings and current controversies. Quarterly Journal of Experimental Psychology, 1975, 27, 1-32.

TAYloR, G. A., \& Juola, J. F. Priming effects on recognition performance. Bulletin of the Psychonomic Society, 1974, 3 , 277-279.

Theios, J., \& Whlter, D. G. Stimulus and response frequency and sequential effects in memory scanning reaction times. Journal of Experimental Psychology, 1974, 102, 1092-1099.

TownSEND, J. R. A note on the identifiability of parallel and serial processes. Perception \& Psychophysics, 1971, 10, 161-163.

Wattenbarger, B. L.. \& Pachella, R. G. The effect of memory load on reaction time in character classification. Perception \& Psychophysics, 1972, 12, 100-102.

Williams, J. D. Memory ensemble selection in human information processing. Journal of Experimental Psychology, 1971, 88, 231-238.

Wingfield, A., \& Branca, A. A. Strategy in high-speed memory search. Joumal of Experimental Psychology, 1970, 83, 63-67.

\section{NOTES}

1. This present paper will consistently speak of a "serial search of memory," although the authors are aware that nothing in the present data speaks against a parallel search that is mathematically equivalent to a serial one (Townsend, 1971).

2. This prediction rests upon the assumption that the linear function relating RT to list length over the range one to four can be extrapolated to lists of up to eight items in length. Available evidence (Wingfield \& Branca, 1970) indicates that such an assumption is tenable. If the true function is negatively accelerated beyond four items, then the exhaustive search strategy would predict that the two-category functions would have a slope somewhat less than twice the slope of the onecategory functions.

3. Homa (1973) also reported that repeating the category of a probe of a list containing three or five semantic categories facilitated RT, but he found that category repetition affected the zero intercept but not the slope of the RT function. This finding may be compatible with the present finding of a slope effect, since Homa's subjects did seem to be performing a selective search of memory. Category repetition may have affected his category comparison stage (reflected in the zero intercept, as Homa plotted his data), while such a stage was absent in the present experiments. Here, category repetition affected the item comparison stage, as described below.

4. The present data do allow some alternative assumptions about the underlying process. For instance, $p$ may be interpreted as the probability that subjects successfully establish two distinct sublists in memory, rather than as the probability of terminating a search. However, the data do rule out some other, plausibie, assumptions. One might expect that successive probes of one category would cumulate in their effect, as if probing a category increased the memory strength of its members. This does not seem to be the case. The weighted mean slope of the functions obtained upon the first repetition of a category in Experiment III was $40.3 \mathrm{msec} / \mathrm{item}$, while the mean slope of the functions obtained upon the second and later immediate repetitions of a category was $42.8 \mathrm{msec} / \mathrm{item}$, with no consistent differences among these later repetitions.

(Received for publication December 30, 1975; revision accepted March 4, 1975.) 